\title{
Longitudinal Study of Infection with Borrelia spp. in Questing Ticks from North-Western Spain
}

\author{
Susana Remesar, ${ }^{1}$ Pablo Díaz, Jose Manuel Venzal, ${ }^{2}$ Alberto Prieto, \\ Agustín Estrada-Peña, ${ }^{3}$ Ceferino Manuel López, ${ }^{1}$ Rosario Panadero, \\ Gonzalo Fernández, ${ }^{1}$ Pablo Díez-Baños, ${ }^{1}$ and Patrocinio Morrondo ${ }^{1}$
}

\begin{abstract}
Introduction: Borrelia burgdorferi sensu lato (s.l.), the causative agent of Lyme borreliosis, is the most prevalent tick-borne pathogen in Europe, where it is mainly transmitted by Ixodes ricinus. This tick also circulates Borrelia miyamotoi, a member of the relapsing fever group of species.

Objectives: A longitudinal study was performed to assess the prevalence of Borrelia spp. in questing ticks. Relationships between Borrelia prevalence in ticks and some variables such as tick development stage, sampling area, and questing tick density were assessed; in addition, the distribution of B. burgdorferi s.l. was analyzed to establish the periods of acarological risk.

Methods: Ticks were collected monthly by flagging in three different ecological areas (coast, plateau, and mountain) in north-western Spain during a 2-year study. Borrelia DNA was detected by PCR, targeting the flagellin $(f l a)$ gene. Positive samples were also characterized at the rrfA-rrlB intergenic spacer region and the glycerophosphodiester phosphodiesterase (GlpQ) gene.

Results: B. burgdorferi s.l. DNA was detected in $11.84 \%$ of I. ricinus. Five Lyme Borrelia species were identified (Borrelia afzelii, B. burgdorferi sensu stricto, Borrelia garinii, Borrelia lusitaniae, and Borrelia valaisiana). One single relapsing fever species (B. miyamotoi) was detected (0.85\%). Questing Ixodes frontalis, Ixodes acuminatus, Dermacentor reticulatus, and Dermacentor marginatus yield negative results. The prevalence of $B$. burgdorferi s.l. was significantly higher in female ticks and in the mountain area. In addition, a seasonal pattern in the B. burgdorferi s.l. prevalence distribution throughout the study was not detected.

Conclusions: The detection of a noticeable prevalence of B. burgdorferi s.l. in questing I. ricinus suggests a high acarological risk, especially in mountain area. There is no evidence of a relationship between the prevalence of $B$. burgdorferi s.l. and the density of questing ticks, nor traces of a seasonal pattern in the values of prevalence in ticks.
\end{abstract}

Keywords: Borrelia burgdorferi s.l., Borrelia miyamotoi, Ixodes ricinus, longitudinal study, north-western Spain

\section{Introduction}

$\mathbf{T}$ ICK-BORNE DISEASES ARE a worldwide public health concern (Dantas-Torres et al. 2012). Ticks are the second most important vectors of pathogens to humans following mosquitoes, but they rank first considering the diversity of carried pathogens (Jongejan and Uilenberg 2004). In this regard, Borrelia burgdorferi sensu lato (s.l.), the causative agent of Lyme borreliosis (LB), is the most prevalent tickborne pathogen in Europe (Barandika et al. 2008).

B. burgdorferi s.l. is mainly transmitted by ticks belonging to the Ixodes ricinus complex. I. ricinus is the main vector in Europe (Gern and Humair 2002). Up-to-now, 10 B. burgdorferi s.l. species have been identified in Europe: Borrelia garinii and Borrelia afzelii are the most frequent and associated with neuroborreliosis and atrophic chronic

\footnotetext{
${ }^{1}$ Departamento de Patología Animal (Grupo INVESAGA), Facultad de Veterinaria, Universidade de Santiago de Compostela, Lugo, Spain.

${ }^{2}$ Laboratorio de Vectores y Enfermedades Transmitidas, Facultad de Veterinaria, Universidad de la República, CENUR Litoral Norte, Salto, Uruguay.

${ }^{3}$ Departamento de Sanidad Animal, Facultad de Veterinaria, Universidad de Zaragoza, Zaragoza, Spain.
} 
acrodermatitis, respectively. Borrelia bavariensis, Borrelia bissettiae, Borrelia finlandensis, Borrelia lusitaniae, Borrelia spielmanii, B. burgdorferi sensu stricto (s.s.), and Borrelia valaisiana are less common (Tappe et al. 2014). In addition, Borrelia miyamotoi, a member of the relapsing fever group, and Borrelia turcica, a species associated to reptiles, have been also found in ticks from Europe (Takano et al. 2012).

It has been reported that the distribution of vector-borne diseases is conditioned by the presence of suitable tick vectors and reservoirs (Estrada-Peña and de la Fuente 2014). Environmental conditions should also be considered since some of them could affect tick mortality rates or timing of tick activity. Thus, several investigations have suggested a relationship between temperature or vapor pressure deficit and the prevalence of B. burgdorferi s.l. in ticks (Gatewood et al. 2009, Estrada-Peña et al. 2011), probably as a consequence of the contact rates between ticks and reservoirs (Estrada-Peña and de la Fuente 2014). The knowledge of factors driving the prevalence of Borrelia in ticks is of major interest (Mysterud et al. 2013). Thus, field studies are the main source of information relating to the distribution of B. burgdorferi $\mathrm{s}$.l. with the questing activity of their tick vectors.

LB is one of the most prevalent vector-borne diseases in Europe (van den Wijngaard et al. 2017). In Spain, LB cases have been detected in all provinces, with an average incidence of 0.25 cases per 100,000 inhabitants and year (Bonet-Alavés et al. 2016); nevertheless, the highest incidence values were detected in northern Spain, considered an endemic area (Hofhuis et al. 2015, Vázquez-López et al. 2015, Bonet-Alavés et al. 2016). Galicia, located in the northwest, is one of the Spanish regions showing the highest incidences of LB, especially the province of Lugo (2.96/100,000 inhabitants and year) where high percentages of questing ticks were also positive to $B$. burgdorferi s.l. (Vázquez-López et al. 2015, Bonet-Alavés et al. 2016, Díaz et al. 2017); in fact, a noticeable increase of LB incidence in humans has been detected in this region from 2007 (2.64 cases/100,000 inhabitants/ year) to 2012 (11.61 cases/100,000 inhabitants/year) (VázquezLópez et al. 2015). Thus, we performed a 2-year longitudinal study to assess the prevalence of Borrelia spp. in ticks collected monthly in three different ecological areas from northwestern Spain. The analysis of the monthly distribution of B. burgdorferi s.l. prevalence throughout the study will allow capturing the acarological risk in space and time. We further focused on the effect of some variables such as the sampling area and the density and stage of development of questing ticks on the percentage of ticks infected by B. burgdorferi s.l.; this information will be useful for identifying risk areas and periods for acquiring LB, leading to the optimization of diagnosis and treatment of the disease.

\section{Materials and Methods}

\section{Study area}

Field studies were conducted in three different ecological regions (coast, plateau, and mountain) (Lago et al. 2012) of Galicia, a $29,574 \mathrm{~km}^{2}$ region located in north-western Spain (Fig. 1), from November 2015 to October 2017. This region has an Oceanic-Atlantic climate with mild temperatures and high precipitation. Grasses such as the meadow fescue (Festuca pratensis), Kentucky bluegrass (Poa pratensis), and ray grass (Lolium perenne) are the most common herbaceous plants, and oaks (Quercus robur) and sweet chestnut (Castanea sativa) are the major tree species (Pato et al. 2013). One single representative sampling area was chosen in each

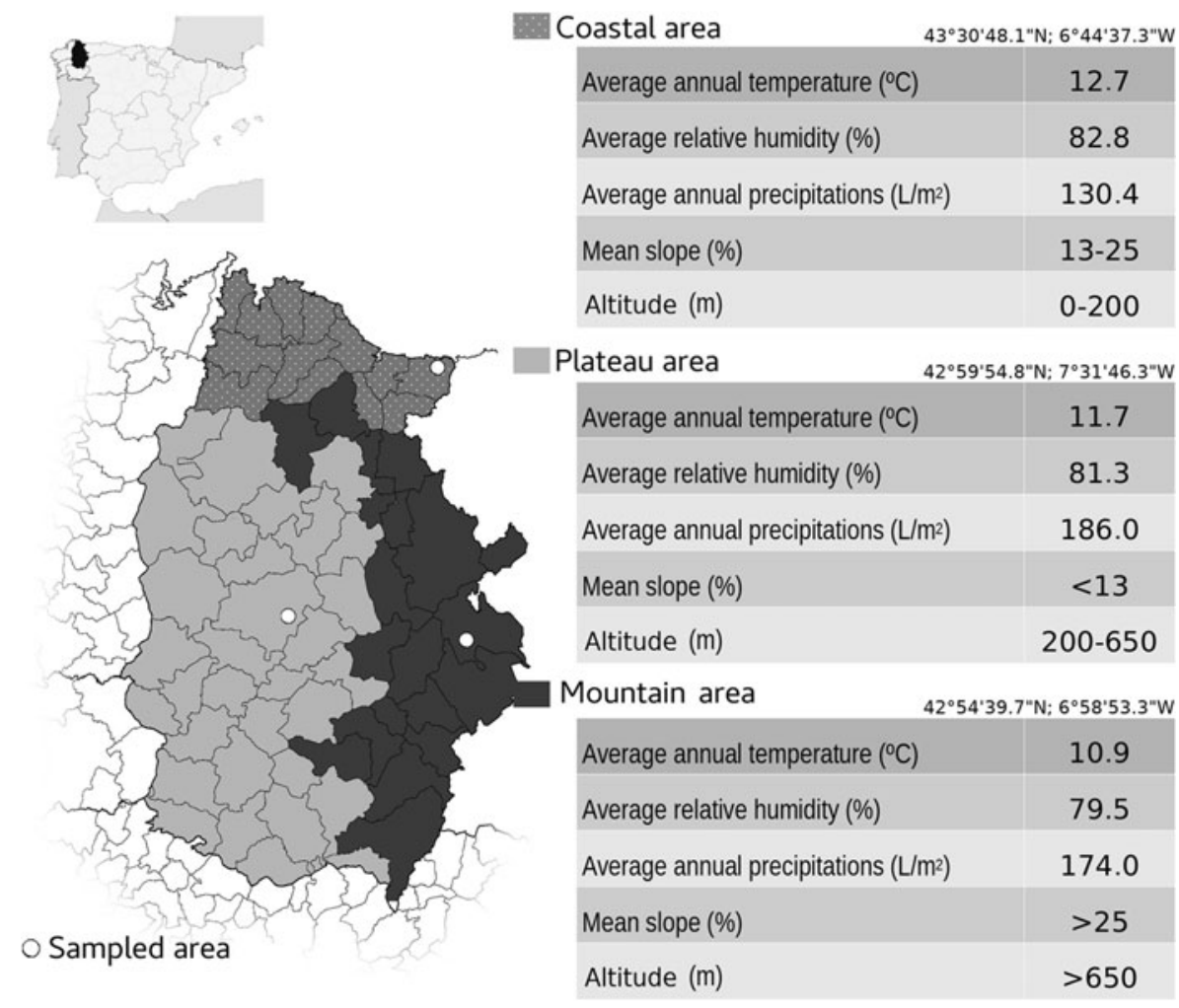

FIG. 1. Localizations and geoclimatic characteristics of the three sampling areas. 
ecological region; distinctive meteorological and topographical features of each area are summarized in Fig. 1.

\section{Tick collection and identification}

Ticks were collected monthly by flagging in each sampling area. A $1 \mathrm{~m}^{2}$ piece of white cotton flannel was passed over the vegetation along the same 300 meters transect. Ticks were picked up from the blanket at 5-10-meter intervals and stored in tubes with $70 \%$ ethanol. A total of 6956 questing ticks were collected. Ticks were identified to species and stage based on morphological features (Pérez-Eid 2007, Estrada-Peña et al. 2017). Five species were found: I. ricinus (652 larvae, 5767 nymphs, 227 males, and 258 females), Dermacentor marginatus (4 males and 15 females), Dermacentor reticulatus ( 7 males and 10 females), Ixodes frontalis (1 larva and 14 nymphs), and a single male of Ixodes acuminatus. Tick specimens were stored in $100 \%$ ethanol at $-20^{\circ} \mathrm{C}$ until DNA extraction.

\section{DNA extraction and detection of Borrelia spp.}

The minimum number of ticks to be processed for DNA extraction was calculated with a $95 \%$ confidence interval and a 5\% type II error to detect differences of $10 \%$ in the prevalence of Borrelia spp. in ticks between sampling areas. We thus analyzed 652 nymphs, 202 females, and 202 males of I. ricinus, together with 12 I. frontalis nymphs and all collected D. marginatus, D. reticulatus, and I. acuminatus.

Each tick was longitudinally cut with a sterile scalpel and homogenized in $200 \mu \mathrm{L}$ of Tissue Lysis Buffer using a tissue homogenizer (MagNaLyser; Roche, Germany) at $6000 \mathrm{rpm}$ during 60 s. DNA was extracted using a commercial kit (High Pure PCR Template Preparation Kit; Roche Diagnostics $\mathrm{GmbH}^{\circledR}$, Mannheim, Germany), following the manufacturer's instructions. Samples were analyzed by a nested PCR targeting the flagellin $(f l a)$ gene, using previously described protocols (Barbour et al. 1996, Stromdahl et al. 2003). Positive samples were selected and sequenced; sequences were aligned and edited using ChromasPro (Technelysium, Brisbane, Australia), and consensus sequences were scanned against the GenBank database using the Basic Local Alignment Search Tool (BLAST 2019; http://blast.ncbi.nlm .nih.gov/Blast.cgi). To confirm fla results, a number of those B. burgdorferi s.l. samples showing identical sequences at the $f l a$ gene were subjected to a specific PCR, targeting the rrfA-rrlB intergenic spacer region (IGS) as previously reported (Derdáková et al. 2003). Similarly, the isolates identified as $B$. miyamotoi were subjected to a PCR, targeting the glycerophosphodiester phosphodiesterase (GlpQ) gene, specific for relapsing fever Borrelia spp. (Hovius et al. 2013). All fla-positive B. burgdorferi s.l. samples were analyzed at the GlpQ gene, and those positive to B. miyamotoi at the IGS, for detecting mixed infections. Unique sequences identified in this study were deposited in GenBank under accession numbers MK256765 to MK256778.

\section{Statistical analysis}

The possible influence of the sampling area and the stage of development of ticks on the prevalence of B. burgdorferi s.l. in I. ricinus was analyzed using a logistic regression. Factors were eliminated from the initial model using a backward and forward conditional method based on the
Akaike Information Criterion value to build the best model, and all pairwise interactions were evaluated. Odds ratio values were computed by raising " $\mathrm{e}$ " to the power of the logistic coefficient over the reference category. In addition, the influence of the studied variables on the prevalence of each B. burgdorferi s.l. species was analyzed by means of a chi-squared test. The possible relationship between the density of I. ricinus and the prevalence of B. burgdorferi s.l. in each season was assessed using a Spearman correlation. All statistical analyses were performed using the statistical software R (R Core Team 2018).

\section{Results}

Borrelia spp. DNA (fla gene) was detected in 130 out of 1056 I. ricinus ticks (12.31\%). No Borrelia-positive I. frontalis, I. acuminatus, D. reticulatus, and D. marginatus were detected. All fla-positive samples were successfully sequenced; in addition, all PCRs targeting the IGS or the GlpQ gene were positive, and sequence analysis confirmed fla results. Lyme Borrelia species were predominant since they were found in 125 positive ticks $(96.15 \%)$, whereas relapsing fever species were detected in 9 I. ricinus (6.92\%). Mixed infections with both Lyme and relapsing fever Borrelia species were detected in three nymphs and one $I$. ricinus female (3.07\%). Five B. burgdorferi s.l. species plus $B$. miyamotoi were identified. B. afzelii was the most frequently recorded, followed by $B$. garinii and B. valaisiana. B. burgdorferi s.s., B. lusitaniae, and B. miyamoto $i$ were only occasionally found (Table 1). The detected co-infections included B. miyamotoi-B. valaisiana $(n=2)$ and B. miyamotoi-B. garinii $(n=2)$. Most Borrelia spp. sequences were identical to reference sequences deposited in the GenBank database or showed a single-nucleotide polymorphism.

The total prevalence of LB spirochetes was significantly higher in the mountain area compared to plateau or coastal regions (Table 2). B. miyamotoi was detected in all sampling areas with prevalences lower than $2 \%$. The prevalence of all B. burgdorferi s.l. species, except for B. valaisiana, was also highest in the mountain (Table 1), but these differences were only significant for B. afzelii $\left(\chi^{2}=16.498 ; p<0.001\right)$. In addition, the mountain showed the highest diversity of species, since all the five B. burgdorferi s.l. species and B. miyamotoi were identified (Table 1). B. lusitaniae was not found in either the plateau or coastal areas, whereas B. miyamotoi was not detected in the plateau area.

All identified Borrelia species were found in nymphs and adults of I. ricinus (Table 1). The individual prevalence of B. burgdorferi s.l. was significantly higher in females than in nymphs or males (Table 2). Similarly, B. miyamotoi and all $B$. burgdorferi s.l. species were more frequent in females, except for B. burgdorferi s.s. that was more prevalent in males (Table 1) without significant differences $(p>0.05)$. No correlation between tick density and Borrelia spp. prevalence was found with the Spearman correlation test $(p>0.05)$. A seasonal pattern of prevalence of Borrelia spp. in questing I. ricinus ticks was not found (Fig. 2). Positive ticks were found throughout the year regardless the area of collection.

\section{Discussion}

Our data reveal that $I$. ricinus is the most abundant questing tick and the only carrier of B. burgdorferi s.l. in 


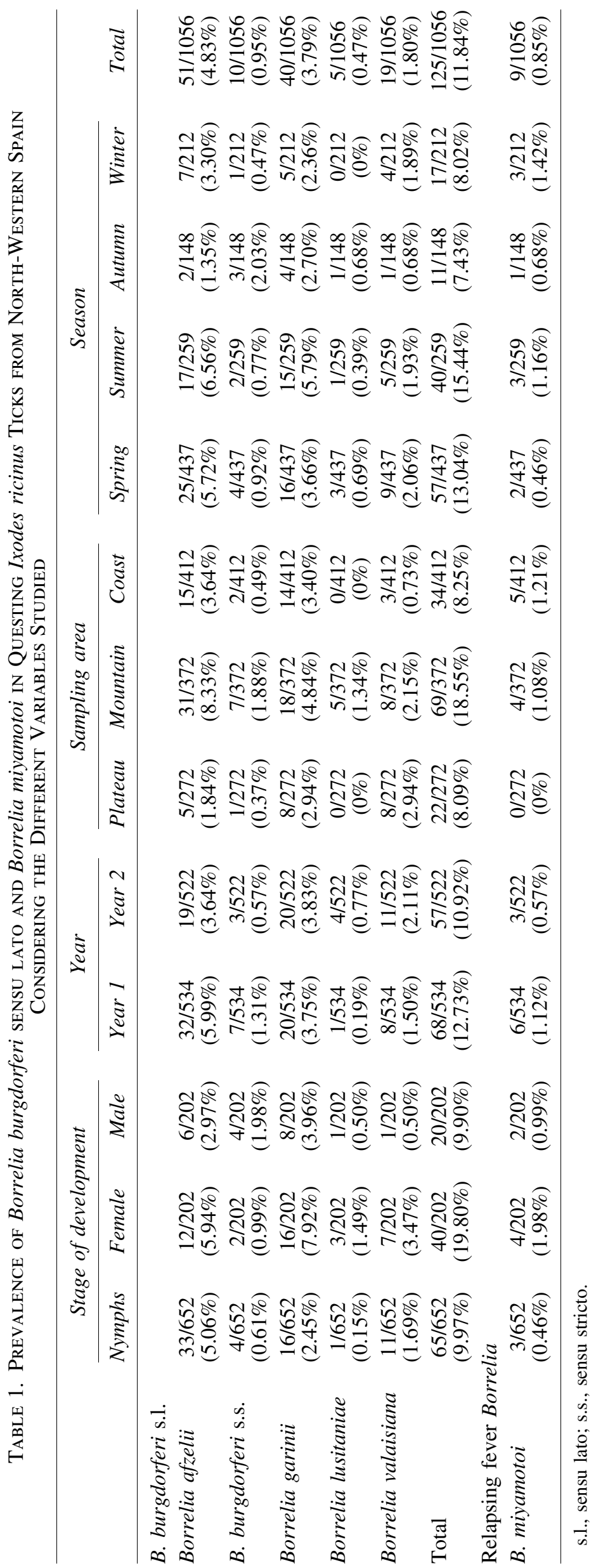


Table 2. Logistic Regression Model FOR THE PREVALENCE OF BorRelia SPP. FACTORS WERE REMOVED Following THE AKaIKe INFORMATION Criterion Value Until the Best Model was Built

\begin{tabular}{lccccc}
\hline \multicolumn{7}{c}{ Estimate } & $\mathrm{Z}$-value & $\operatorname{Pr}(>|\mathrm{t}|)$ & OR & $95 \%$ CI \\
\hline $\begin{array}{l}\text { Borrelia spp. } \\
\text { Intercept }\end{array}$ & -0.8373 & -4.146 & $<0.001$ & 0.43 & $0.29-0.64$ \\
$\begin{array}{l}\text { Females } \\
\text { Nymphs }\end{array}$ & -0.7255 & -3.236 & 0.001 & 0.48 & $0.31-0.76$ \\
$\begin{array}{l}\text { Males } \\
\text { Mountain }\end{array}$ & -0.9607 & -3.195 & 0.001 & 0.38 & $0.21-0.68$ \\
$\quad$ area & - & - & - & - & - \\
$\begin{array}{l}\text { Plateau area } \\
\text { Coastal area }\end{array}$ & -1.1725 & -4.252 & $<0.001$ & 0.31 & $0.18-0.52$ \\
\hline
\end{tabular}

CI, confidence interval; OR, odds ratio.

north-western Spain, agreeing with the many studies carried out in Europe (Gern and Humair 2002, Strnad et al. 2017). Density of other tick species was low, and B. burgdorferi s.l. remained undetected in I. acuminatus, I. frontalis, D. reticulatus, and D. marginatus. I. frontalis is an ornithophilic tick found in both nests and vegetation and considered a competent vector of B. burgdorferi s.l. (Estrada-Peña et al. 1995, Heylen et al. 2013). In addition, the presence of B. burgdorferi s.l. DNA in questing Dermacentor spp. from Europe has been reported in a limited number of investigations, with lower prevalence than that detected in I. ricinus and never exceeding 3.4\% (Bonnet et al. 2013, Reye et al. 2010, Zajac et al. 2017). It has been suggested that those results may be due to the inactivation of B. burgdorferi s.l. spirochetes by the immune system of Dermacentor since these ticks are not considered competent vectors (Johns et al. 2001, Grubhoffer et al. 2005).

Our results confirm that B. burgdorferi s.l. is prevalent and widely distributed in questing I. ricinus in Galicia (northwestern Spain). These bacteria are considered endemic in other northern regions of Spain, with largely variable prevalence ranging from $0.6 \%$ to $7.1 \%$ in nymphs and from $2.1 \%$ to $6 \%$ in adults (Barral et al. 2002, Espí et al. 2017). Our results showed that the epidemiological situation in Galicia involves a great risk for transmission of LB agents to humans, paralleling the increasing incidence of patients with LB recently reported in this region (Vázquez-López et al. 2015).

Significant variations in the prevalence of $B$. burgdorferi s.l. in questing ticks among variable ecological conditions were already reported (Gray et al. 1995, Jouda et al. 2004, Richter et al. 2013). Therefore, our results fill the gap providing human health authorities with the prevalence of Borrelia spp. in questing ticks. These data pinpoint the significantly higher prevalence of $B$. burgdorferi s.l. in the mountain, where the highest incidence of LB was previously reported (Vázquez-López et al. 2015). It seems that the correct conditions for spatial overlapping of vectors and reservoirs occur in this area, where the highest altitude ( $>650$ meters) and lowest average annual temperature values $\left(<10.9^{\circ} \mathrm{C}\right)$ were recorded (Fig. 1). These differences could be related to variables such as climate, density of reservoirs, land use, and human actions on landscape driving habitat fragmentation. It has been reported that most of these variables locally affect the prevalence of Borrelia spp. in questing ticks (Estrada-Peña and de la Fuente 2014). As an example, higher prevalence of B. burgdorferi s.s. and B. garinii was reported in ticks collected in oak forests than those from pine forests (Gray et al. 1998, Tack et al. 2011, Ruyts et al. 2017) because the former provide a better microclimate for ticks and show a higher density of suitable reservoirs. Our study addressed the importance of the qualitative features of landscape, considering only the differences observed among the three surveyed ecosystems. Obvious differences in the prevalence of Borrelia spp. were found, but a rigorous analysis of the impact of climate variables on the activity of local reservoirs warrants future assessment.

We did not find a statistical correlation between the density of questing nymphs and adults of I. ricinus and the prevalence of B. burgdorferi s.l. in ticks. In addition, the prevalence of B. burgdorferi s.l. in I. ricinus was similar through both years of study and a pattern on the Borrelia prevalence distribution was not detected, agreeing with previous reports (Jouda et al. 2004, Estrada-Peña et al. 2011, James et al. 2012). Nevertheless, other studies suggested a seasonal pattern in both questing ticks positive to Borrelia spp. (Talleklint and Jaenson 1996) and LB patients (Kurtenbach et al. 2006); these investigations were performed in European regions with harsh winters, suggesting that different variables, especially low winter temperatures, may negatively affect the activity of local reservoirs leading to a decrease in the percentage of Borreliapositive questing ticks. In contrast, less marked seasonal climatic fluctuations, such as those recorded in other European regions, including north-western Spain, allow a more constant reservoir activity throughout the year and thus may explain the lack of a seasonal pattern in the prevalence of $B$. burgdorferi s.l. in questing ticks. Considering the absence of this temporal pattern, the risk of acquiring LB will only increase with tick density due to a higher risk of exposure to tick bites.

The prevalence of $B$. burgdorferi s.l. was significantly higher in female I. ricinus than in nymphs or males, as reported in other studies carried out in Europe (Jouda et al. 2004, Kampen et al. 2004, Soleng et al. 2013, Sormunen et al. 2015, Espí et al. 2017), a feature already linked to the number of blood meals or even the amount of blood consumed during the feeding process (Matuschka et al. 1993, Dusbábek 1996).

Borrelia garinii and B. afzelii were the predominant species, matching results of a recent study carried out in Asturias, an adjacent area from north-western Spain (Espí et al. 2017). Both species were also most commonly reported in human patients from Galicia (Vázquez-López et al. 2016a, b). These differences in the ecological distribution of $B$. burgdorferi s.l. species have been related to the presence of a particular reservoir composition, since these spirochetes infect different groups of animals (Kurtenbach et al. 2002, Estrada-Peña et al. 2011). Thus, B. afzelii and B. burgdorferi s.s. are associated with rodents (Huegli et al. 2002, Hanincová et al. 2003), B. valaisiana and B. garinii with birds (Hanincová et al. 2003), and B. lusitaniae with lizards (Richter and Matuschka 2006). These relationships reflect the extremely local regulatory factors that affect the circulation of the species of $B$. burgdorferi s.l.

The finding of B. miyamotoi in both nymphal and adult I. ricinus from coastal and mountain areas confirms that this species is circulating in north-western Spain. Since this spirochete was identified as pathogenic for humans (Wagemakers et al. 2015), its presence in the studied areas should be considered in the differential diagnosis of clinical patients (Palomar et al. 2018). 

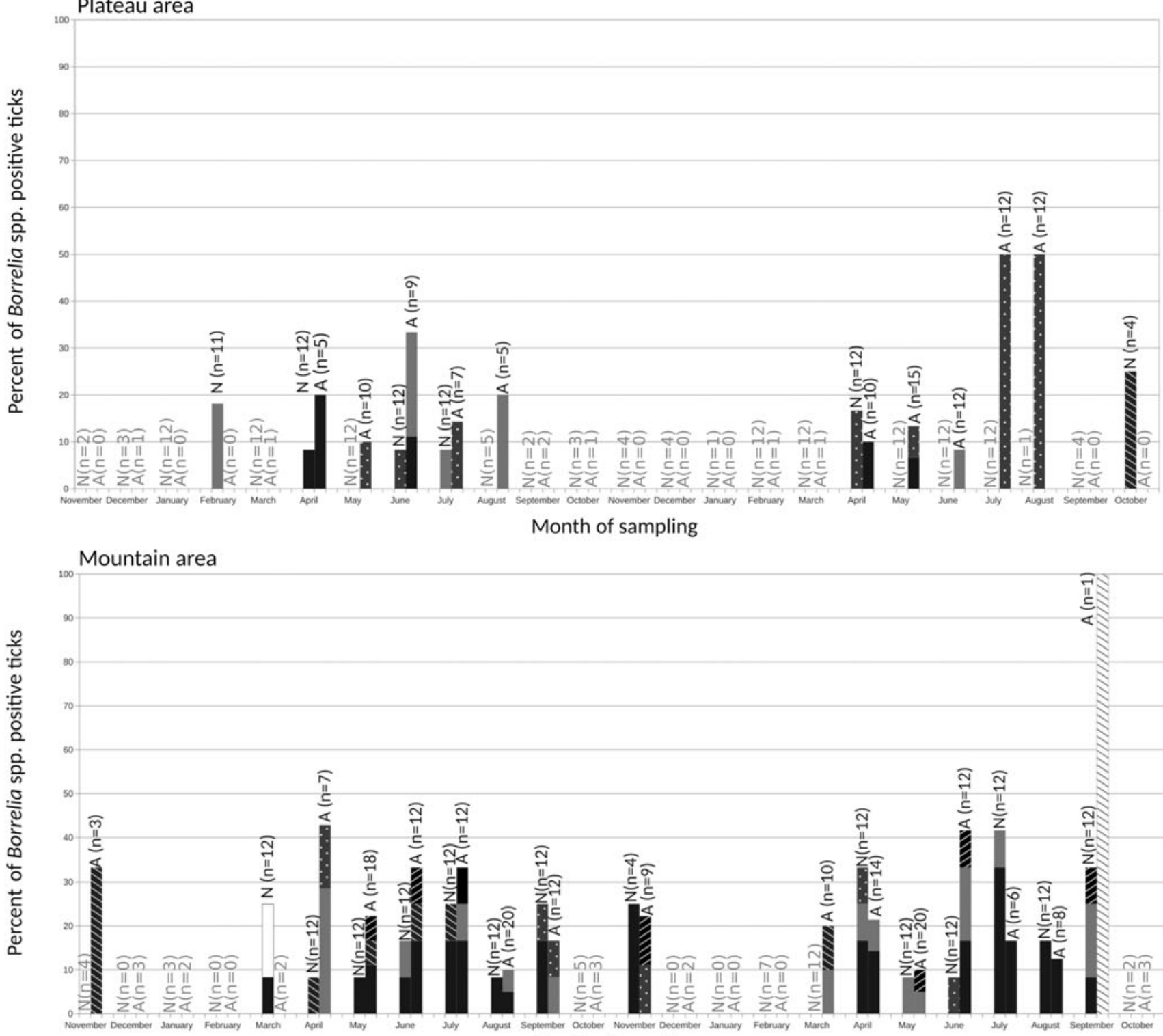

Coastal area

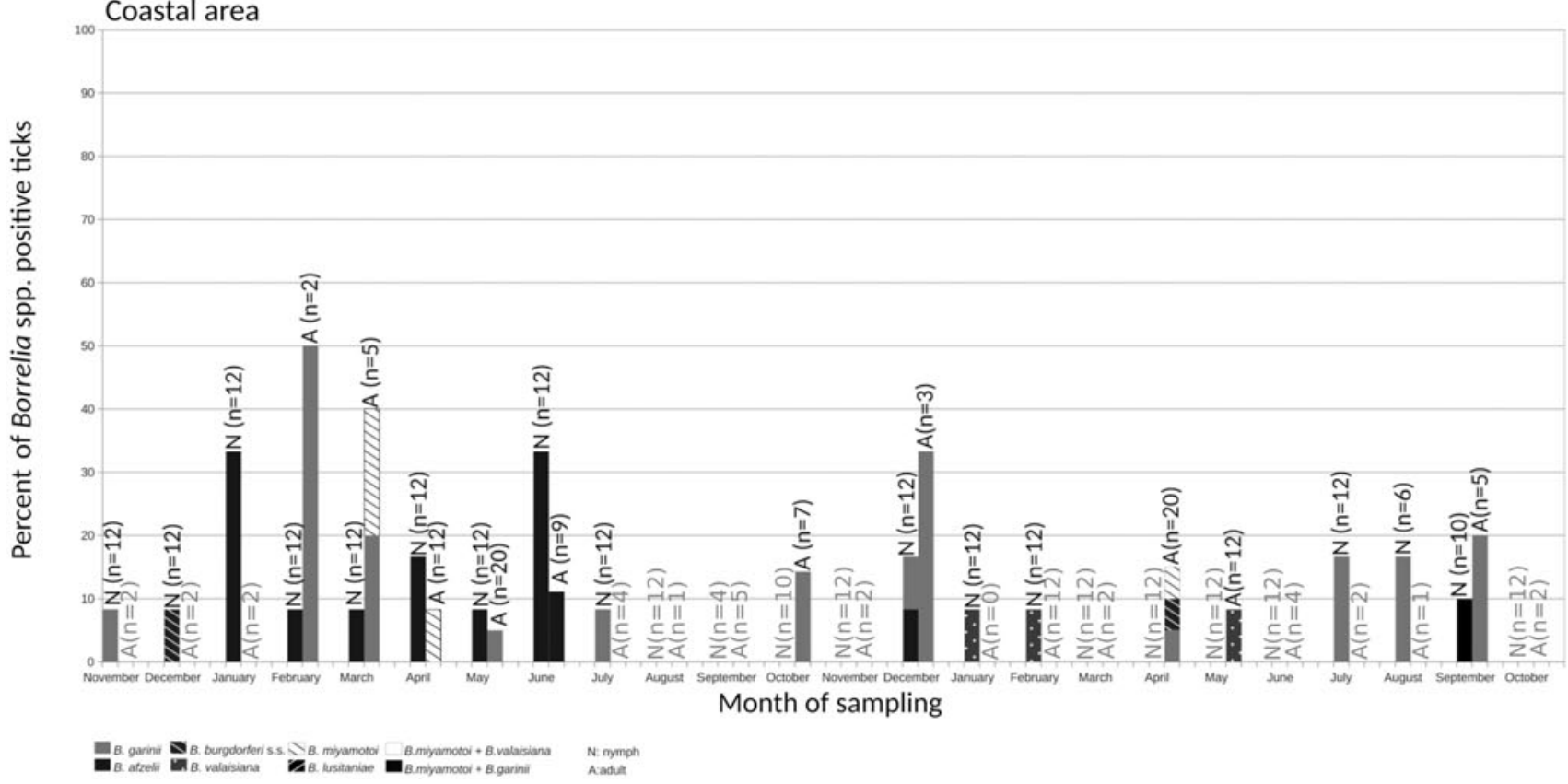

FIG. 2. Borrelia spp. prevalence in questing Ixodes ricinus ticks during both years of study. 


\section{Conclusions}

The noticeable prevalence of $B$. burgdorferi s.l. in questing I. ricinus ticks from three different ecological areas in northwestern Spain suggests a high acarological risk, especially in those regions showing the highest altitude and lowest average annual temperature. In addition, the prevalence of $B$. burgdorferi s.l. in questing I. ricinus was not related to the density of questing ticks in the studied areas. There is no evidence of a monthly or seasonal pattern in the prevalence of $B$. burgdorferi s.l. in questing ticks. Consequently, the acarological risk for acquiring LB increases only with the density of questing ticks. Further research assessing the abundance and relative contribution of reservoirs in the area and their role circulating the pathogens is needed. Such information could be used to determine and predict risk areas for acquiring LB.

\section{Acknowledgments}

This research was supported by the Programme for Consolidating and Structuring Competitive Research Groups (GRC2015/003; Xunta de Galicia, Spain) and by a predoctoral grant (European Social Fund, Secretaría Xeral de Universidades, Xunta de Galicia).

\section{Author Disclosure Statement}

No competing financial interests exist.

\section{References}

Barandika JF, Hurtado A, Garcia-Sanmartin J, Juste RA, et al. Prevalence of Tick-borne zoonotic bacteria in questing adult ticks from Northern Spain. Vector Borne Zoonotic Dis 2008; 6:829-835.

Barbour AG, Maupin GO, Teltow GJ, Carter CJ, et al. Identification of an uncultivable Borrelia species in the hard tick Amblyomma americanum: Possible agent of a Lyme diseaselike illness. J Infect Dis 1996; 2:403-409.

Barral M, Garcia-Perez AL, Juste RA, Hurtado A, et al. Distribution of Borrelia burgdorferi sensu lato in Ixodes ricinus (Acari: Ixodidae) ticks from the Basque Country, Spain. J Med Entomol 2002; 39:177-184.

BLAST. Blastn suite. 2019. Available at https://blast.ncbi.nlm .nih.gov/Blast.cgiPAGE_TYPE=BlastSearch

Bonet-Alavés E, Guerrero-Espejo A, Cuenca-Torres M, Gimeno-Vilarrasa F. Incidence of Lyme disease in Spain [in Spanish]. Med Clin (Barc) 2016; 147:88-89.

Bonnet S, de la Fuente J, Nicollet P, Liu X, et al. Prevalence of tick-borne pathogens in adult Dermacentor spp. ticks from nine collection sites in France. Vector Borne Zoonotic Dis 2013; 13:226-236.

Dantas-Torres F, Chomel, BB, Otranto D. Ticks and tick-borne diseases: A One Health perspective. Trends Parasitol 2012; 10 : 437-446.

Derdáková M, Halanova M, Stanko M, Stefancikova A, et al. Molecular evidence for Anaplasma phagocytophilium and Borrelia burgdorferi sensu lato in Ixodes ricinus ticks from Eastern Slovakia. Ann Agric Environ Med 2003; 10:269-271.

Díaz P, Arnal JL, Remesar S, Perez-Creo A, et al. Molecular identification of Borrelia spirochetes in questing Ixodes ricinus from northwestern Spain. Parasit Vectors 2017; 10:615.

Dusbábek F. Nymphal sexual dimorphism in the sheep tick Ixodes ricinus (Acari: Ixodidae). Folia Parasitol 1996; 43: 75-79.
Espí A, Del Cerro A, Somoano A, Garcia V, et al. Borrelia burgdorferi sensu lato prevalence and diversity in ticks and small mammals in a Lyme borreliosis endemic Nature Reserve in North-Western Spain. Incidence in surrounding human populations. Enferm Infecc Microbiol Clin 2017; 35 : 563-568.

Estrada-Peña A, de la Fuente J. The ecology of ticks and epidemiology of tick-borne viral diseases. Antiviral Res 2014; 108:104-128.

Estrada-Peña A, Mihalca A, Petney TN. Ticks of Europe and North Africa. Cham, Switzerland: Springer, 2017.

Estrada-Peña A, Ortega C, Sanchez N, DeSimone L, et al. Correlation of Borrelia burgdorferi sensu lato prevalence in questing Ixodes ricinus ticks with specific abiotic traits in the Western Palearctic. Appl Environ Microbiol 2011; 11:38383845.

Estrada-Peña A, Oteo JA, Estrada-Pena R, Gortazar C, et al. Borrelia burgdorferi sensu lato in ticks (Acari: Ixodidae) from two different foci in Spain. Exp Appl Acarol 1995; 19: 173-180.

Gatewood AG, Liebman KA, Vourc'h G, Bunikis J, et al. Climate and tick seasonality are predictors of Borrelia burgdorferi genotype distribution. Appl Environ Microbiol 2009; 8:2476-2483.

Gern L, Humair PF. Ecology of Borrelia burgdorferi sensu lato in Europe, p 149-174. Lyme borreliosis: Biology, Epidemiology, and Control. Wallingford, United Kingdom: CAB International, 2002.

Gray JS, Kahl O, Janetzki C, Stein J, et al. The spatial distribution of Borrelia burgdorferi-infected Ixodes ricinus in the Connemara region of County Galway, Ireland. Exp Appl Acarol 1995; 9:163-172.

Gray JS, Kahl O, Robertson JN, Daniel M, et al. Lyme borreliosis habitat assessment. Zentralbl Bakteriol 1998; 287:211-228.

Grubhoffer L, Golovchenko M, Vancová M, ZacharovováSlavícková K, et al. Lyme borreliosis: Insights into tick-/hostborrelia relations. Folia Parasitol (Praha) 2005; 52:279-294.

Hanincova K, Schafer SM, Etti S, Sewell HS, et al. Association of Borrelia afzelii with rodents in Europe. Parasitology 2003; 126:11-20.

Heylen D, Tijsse E, Fonville M, Matthysen E, et al. Transmission dynamics of Borrelia burgdorferi s.l. in a bird tick community. Environ Microbiol 2013; 15:663-673.

Hofhuis A, Harms M, Bennema S, van den Wijngaard C, et al. Physician reported incidence of early and late Lyme borreliosis. Parasit Vectors 2015; 8:161.

Hovius JW, de Wever B, Sohne M, Brouwer MC, et al. A case of meningoencephalitis by the relapsing fever spirochaete Borrelia miyamotoi in Europe. Lancet 2013; 382:658.

Huegli D, Hu CM, Humair PF, Wilske B, et al. Apodemus species mice are reservoir hosts of Borrelia garinii OspA serotype 4 in Switzerland. J Clin Microbiol 2002; 40:47354737.

James MC, Bowman AS, Forbes K, Lewis F, et al. Environmental determinants of Ixodes ricinus ticks and the incidence of Borrelia burgdorferi sensu lato, the agent of Lyme borreliosis, in Scotland. Parasitology 2012; 140:237-246.

Johns R, Ohnishi J, Broadwater A, Sonenshine DE, et al. Contrasts in tick innate immune responses to Borrelia burgdorferi challenge: Immunotolerance in Ixodes scapularis versus immunocompetence in D. variabilis (Acari: Ixodidae). J Med Entomol 2001; 38:99-107.

Jongejan F, Uilenberg G. The global importance of ticks. Parasitology 2004; 129:S3-S14. 
Jouda F, Perret JL, Gern L. Density of questing Ixodes ricinus nymphs and adults infected by Borrelia burgdorferi sensu lato in Switzerland: Spatio-temporal pattern at a regional scale. Vector Borne Zoonotic Dis 2004; 4:23-32.

Kampen H, Rotzel DC, Kurtenbach K, Maier WA, et al. Substantial rise in the prevalence of Lyme borreliosis spirochetes in a region of western Germany over a 10-year period. Appl Environ Microbiol 2004; 70:1576-1582.

Kurtenbach K, De Michelis S, Etti S, Schäfer SM, et al. Host association of Borrelia burgdorferi sensu lato-The key role of host complement. Trends Microbiol 2002: 10:74-79.

Kurtenbach K, Hanincová K, Tsao JI, Margos G, et al. Fundamental processes in the evolutionary ecology of Lyme borreliosis. Nat Rev Microbiol 2006; 4:660-669.

Lago N, López C, Panadero R, Cienfuegos S, et al. Seroprevalence and risk factors associated with Visna/Maedi virus in semi-intensive lamb-producing flocks in northwestern Spain. Prev Vet Med 2012; 103:163-169.

Matuschka FR, Heiler M, Eiffert H, Fischer P, et al. Diversionary role of hoofed game in the transmission of lymedisease spirochetes. Am J Trop Med Hyg 1993; 48:693-699.

Mysterud A, Easterday WR, Qviller L, Viljugrein H, et al. Spatial and seasonal variation in the prevalence of Anaplasma phagocytophilum and Borrelia burgdorferi sensu lato in questing Ixodes ricinus ticks in Norway. Parasit Vectors 2013; 6:187.

Palomar AM, Portillo A, Santibáñez P, Santibáñez S, et al. Borrelia miyamotoi: Should this pathogen be considered for the diagnosis of tick-borne infectious diseases in Spain? Enferm Infecc Microbiol Clin 2018; 36:568-571.

Pato FJ, Panadero R, Vázquez L, López CM, et al. Seroprevalence of Borrelia burgdorferi sensu lato in roe deer (Capreolus capreolus) from northwestern Spain. J Zoo Wildl Med 2013; 44:660-665.

Pérez-Eid C. Les tiques. Identification, biologie, importance médicale et vétérinaire. [Ticks. identification, biology, medical and veterinary importance] Ed. Coll. Monographies de microbiologie. Lavoisier, 2007.

R Core Team. 2018. R: A Language and Environment for Statistical Computing. Available at https://www.R-project.org

Reye AL, Hubschen JM, Sausy A, Muller CP. Prevalence and seasonality of tick-borne pathogens in questing Ixodes ricinus ticks from Luxembourg. Appl Environ Microbiol 2010; 76: 2923-2931.

Richter D, Matuschka FR. Perpetuation of the Lyme disease spirochete Borrelia lusitaniae by lizards. Appl Environ Microbiol 2006; 72:4627-4632.

Richter D, Schröder B, Hartmann NK, Matuschka FR. Spatial stratification of various Lyme disease spirochetes in a Central European site. FEMS Microbiol Ecol 2013; 3:738-744.

Ruyts SC, Frazer-Mendelewska E, Van den Berge K, Verheyen $\mathrm{K}$, et al. Molecular detection of tick-borne pathogens Borrelia afzelii, Borrelia miyamotoi and Anaplasma phagocytophilum in Eurasian red squirrels (Sciurus vulgaris). Eur J Wildlife Res 2017; 63:3.

Soleng A, Kjelland V. Borrelia burgdorferi sensu lato and Anaplasma phagocytophilum in Ixodes ricinus ticks in Brønnøysund in northern Norway. Ticks Tick Borne Dis 2013; 4: $218-221$.

Sormunen JJ, Klemola T, Vesterinen EJ, Vuorinen I, et al. Assessing the abundance, seasonal questing activity, and
Borrelia and tick-borne encephalitis virus (TBEV) prevalence of Ixodes ricinus ticks in a Lyme borreliosis endemic area in Southwest Finland. Ticks Tick Borne Dis 2015; 7:208-215.

Strnad M, Hönig V, Růžek D, Grubhoffer L, et al. Europe-wide meta-analysis of Borrelia burgdorferi sensu lato prevalence in questing Ixodes ricinus ticks. Appl Environ Microbiol 2017; 83:15.

Stromdahl EY, Williamson PC, Kollars TM, Evans SR, et al. Evidence of Borrelia lonestari DNA in Amblyomma americanum (Acari: Ixodidae) removed from humans. J Clin Microbiol 2003; 41:5557-5562.

Tack W, Madder M, De Frenne P, Vanhellemont M, et al. The effects of sampling method and vegetation type on the estimated abundance of Ixodes ricinus ticks in forests. Exp Appl Acarol 2011; 54:285-292.

Takano A, Sugimori C, Fujita H, Kadosaka T, et al. A novel relapsing fever Borrelia sp. infects the salivary glands of the molted hard tick, Amblyomma geoemydae. Ticks Tick Borne Dis 2012; 3:259-261.

Talleklint L, Jaenson TGT. Relationship between Ixodes ricinus density and prevalence of infection with Borrelia-like spirochetes and density of infected ticks. J Med Entomol 1996; 33 : 805-811.

Tappe J, Jordan D, Janecek E, Fingerle V, et al. Revisited: Borrelia burgdorferi sensu lato infections in hard ticks (Ixodes ricinus) in the city of Hanover (Germany). Parasit Vectors 2014; 7:441.

van den Wijngaard CC, Hofhuis A, Wong A, Harms MG, et al. The cost of Lyme borreliosis. Eur J Public Health 2017; 27 : 538-547.

Vázquez-López ME, Díez-Morrondo C, Sánchez-Andrade A, Pego-Reigosa R, et al. Manifestaciones articulares en enfermos de Lyme. Reumatol Clin 2016a; 12:327-330.

Vázquez-Lopez ME, Pego-Reigosa R, Diez-Morrondo C, Castro-Gago M, et al. Epidemiology of Lyme disease in a healthcare area in north-west Spain. Gac Sanit 2015; 29:213216.

Vázquez-López ME, Pérez-Pacína R, Díez-Morrondo C, Díaz $\mathrm{P}$, et al. Enfermedad de Lyme en edad pediátrica [in Spanish]. An Pediatr (Barc) 2016b; 84:234-235.

Wagemakers A, Staarink PJ, Sprong H, Hovius JWR. Borrelia miyamotoi: A widespread tick-borne relapsing fever spirochete. Trends Parasitol 2015; 31:260-269.

Zając V, Pinkas J, Wójcik-Fatla A, Dutkiewicz J, et al. Prevalence of serological response to Borrelia burgdorferi in farmers from eastern and central Poland. Eur J Clin Microbiol Infect Dis 2017; 36:437-446.

Address correspondence to: Pablo Díaz, PhD

Departamento de Patología Animal (Grupo INVESAGA) Facultad de Veterinaria Universidade de Santiago de Compostela Pabellón I Planta Baja. Campus Universitario $s / n$ Lugo 27002 Spain

E-mail: pablo.diaz@usc.es 